\title{
ROLE OF MDCT IN ASSESSMENT OF PLEUROPNEUMONIC CHANGES AFTER BREAST CANCER RADIOTHERAPY.
}

\author{
Hanan M. H. Abuzeid; Eman A. Sh. Geneidi; Haytham M. Nasser; \\ and Nashwa G. Basiouny
}

\begin{abstract}
Radiodiagnosis department, Ain Shams University, Cairo, Egypt

Corresponding author

Nashwa Gad Basiouny Gad.

Mobile: (+2) 01115123672

E.mail:

nashwagad84@gmail.com
\end{abstract}

Received: 21/4/2021

Accepted: 20/4/2021

Online ISSN: 2735-3540

\begin{abstract}
Back ground: Breast cancer radiotherapy plays an important role and can reduce local and regional recurrence, however may be complicated by radiation pneumonitis, the early stage occurs one to three months after treatment characterized mainly by ground glass opacities and consolidate-ion related to radiation portal. The late phase develops six months after the completion of radiation therapy and can progress for as long as two years manifested by atelectactic bands bronchiectasis and lung fibrosis. MDCT has an important role in assessment of lung and pleural changes with grading of these changes.
\end{abstract}

Aim of the work: To show the role of MDCT in assessment of pleuropneumonic changes after breast cancer radiotherapy.

Patients and methods: This study included 25 breast cancer patients managed with chemotherapy and surgery followed by $R T$ (January 2017 and April 2020).

Results: The study showed that lung and pleural changes varies from no changes to lung consolidation, fibrosis, bronchiectasis and pleural effusion and thickening which affected by different factors.

Conclusion: MDCT has an important role in assessment of early and late lung changes after breast cancer radiotherapy.

Keywords: Radiotherapy(RT); Radiation pneumonitis(RP); Radiation Fibrosis (RF); Multi-detector computed tomography (MDCT); Radiation induced lung damage (RILD).

\section{INTRODUCTION:}

Breast cancer is the most common cancer diagnosed among women, accounting for nearly 1 in 3 cancers $^{(1)}$. Postoperative radiotherapy plays an important role in the management of breast cancer and can reduce local and regional recurrence, thereby improving outcomes ${ }^{(2)}$. Radiotherapy may be complicated by radiation pneumonitis, the early stage of which occurs one to three months after treatment ${ }^{(3)}$. The late phase also known as fibrosis develops six months after the completion of radiation therapy and can progress for as long as two years. This can produce pleural changes that manifest themselves on CT images as smooth pleural based thickening ${ }^{(4)}$.CT can be used in the diagnosis of radiation pneumonitis, it may show ground glass opacities, consolidation, fibrosis, atelectactic cicatrisation, pulmonary volume $\operatorname{loss} s^{(5)}$. Radiographic changes in radiation fibrosis are confined exclusively to the irradiated area ${ }^{(6)}$.In patients with breast cancer, older age, chest wall irradiation with electrons, and supraclavicular treatment are correlated with increased risk of radiation pneumonitis $^{(7)}$. 


\section{PATIENTS AND METHODS}

This study was approved by the ethics committee of our institution. This study included 25 patients referred from oncologist to Radiodiagnosis Department of Damanhur Oncology Centre between January, 2017 and April 2020.

\section{Inclusion criteria:}

Breast cancer patients managed with breast conserving surgery or modified radical mastectomy followed by radiotherapy (Both sexes are included but with female predilection with no age predilection).

\section{Exclusion criteria:}

Patients with renal insufficiency, patients with contrast agent allergy and patients who are pregnant.

\section{Patient preparation:}

- Informed consent from the patient.

- History taking.

- Laboratory investigation including kidney function tests.

- Detailed explanation of imaging procedures.

- Cannula insertion.

- $1-1.5 \mathrm{ml} / \mathrm{kg}$ body weight of noniodinated contrast media.

- CT examination including: Axial (pulmonary \& mediastinal and bone) windows. Three dimensional reformatting imaging.

- Imaging technique

- The patient will be imaged on full inspiration.

- Intravenous injection of $1.5 \mathrm{ml} / \mathrm{kg}$ body weight of non-ionic contrast agent will be performed by automated injector.

- Image reconstruction using 'bone' algorithm, i.e. high resolution algorithm which reduces standard CT image smoothing.

- Imaging evaluation:

- Patients underwent chest CT scans at three and nine months after completion of radiotherapy. The CT scans were performed during a routine clinical follow up and everything was done in accordance with the clinical practice of the radiation oncology unit.

- Chest symptoms were correlated to CT chest findings.

- History COPD and smoking were correlated to CT chest findings.

The results of this study will be presented as follows:

- CT finding of different pattern of RILD.

- Radiological grading scale of radiation induced pneumonitis.

- Correlation between these grades and clinical and radio-therapeutic parameters.

- The described findings were classified according to different pattern of radiation induced lung damage (RILD), correlation between non dosimetric risk factors and radiation induced lung changes and the proposed radiation pneumonitis grading scale based on CT staging.

\section{Statistical analysis:}

Data were coded and entered using the statistical package for the Social Sciences (SPSS) version 26 (IBM Corp., Armonk, NY, USA). Data was summarized using mean, standard deviation, minimum and maximum in quantitative data and using frequency (count) and relative frequency (percentage) for categorical data. For comparing categorical data, Chi square $(\chi 2)$ test was performed. Exact test was used instead when the expected frequency is less than 5 (Chan, 2003). P-values less than 0.05 were considered as statistically significant. 
Table 1: Radiological CT Grading Scale (Vassilios's scale).

\begin{tabular}{|l|l|l|}
\hline Radiological grade & Grade 0 & No CT findings. \\
\cline { 2 - 4 } & Grade 1 & Ground glass opacities. \\
\cline { 2 - 3 } & Grade 2 & $\begin{array}{l}\text { Ground glass opacities extending beyond the radiation field to } \\
\text { consolidation. }\end{array}$ \\
\cline { 2 - 3 } & Grade 3 & Clear focal consolidation +/- elements of fibrosis. \\
\cline { 2 - 3 } & Grade 4 & $\begin{array}{l}\text { Dense consolidation cicatrisation atelectasis (traction bronchiectasis, } \\
\text { significant pulmonary volume loss and thickening). }\end{array}$ \\
\hline
\end{tabular}

\section{RESULTS:}

A total of 25 managed breast cancer patients with mean age 54 years.

Table 2: Different pattern of Radiation Induced Lung Disease (RILD):

\begin{tabular}{|l|l|c|c|c|c|}
\hline \multicolumn{2}{|c|}{} & \multicolumn{2}{c|}{3 months } & \multicolumn{2}{c|}{9 months } \\
\cline { 3 - 7 } \multicolumn{2}{|c|}{ Ground glass opacities } & Count & $\%$ & Count & $\%$ \\
\cline { 2 - 6 } & $\mathrm{N}$ & 15 & $60.0 \%$ & 8 & $32.0 \%$ \\
\hline \multirow{2}{*}{ Consolidation } & $\mathrm{Y}$ & 13 & $40.0 \%$ & 17 & $68.0 \%$ \\
\cline { 2 - 6 } & $\mathrm{N}$ & 12 & $48.0 \%$ & 9 & $36.0 \%$ \\
\hline \multirow{2}{*}{ Atelctatic bands } & $\mathrm{Y}$ & 9 & $36.0 \%$ & 16 & $64.0 \%$ \\
\cline { 2 - 6 } & $\mathrm{N}$ & 16 & $64.0 \%$ & 9 & $36.0 \%$ \\
\hline \multirow{2}{*}{$\begin{array}{l}\text { Fibrosis with tractional } \\
\text { bronchiectasis }\end{array}$} & $\mathrm{Y}$ & 5 & $20.0 \%$ & 6 & $24.0 \%$ \\
\cline { 2 - 6 } & $\mathrm{N}$ & 20 & $80.0 \%$ & 19 & $76.0 \%$ \\
\hline \multirow{3}{*}{ Pleural effusion } & $\mathrm{Y}$ & 5 & $20.0 \%$ & 3 & $12.0 \%$ \\
\cline { 2 - 6 } & $\mathrm{N}$ & 20 & $80.0 \%$ & 22 & $88.0 \%$ \\
\hline \multirow{2}{*}{ Pleural thickening } & $\mathrm{Y}$ & 3 & $12.0 \%$ & 5 & $20.0 \%$ \\
\cline { 2 - 6 } & $\mathrm{N}$ & 22 & $88.0 \%$ & 20 & $80.0 \%$ \\
\hline
\end{tabular}

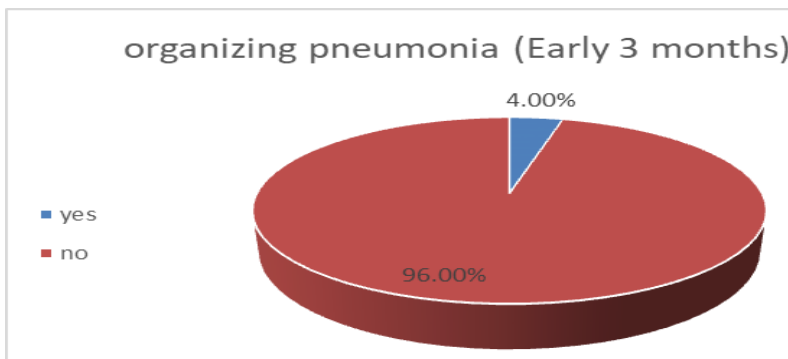

Diagram 1: Organizing pneumonia.

Table 3: Radiological Grading Scale of Radiation Induced Pneumonitis.

\begin{tabular}{|l|l|c|c|c|c|}
\hline \multicolumn{2}{|c|}{} & \multicolumn{2}{c|}{3 months } & \multicolumn{2}{c|}{9 months } \\
\cline { 3 - 6 } \multicolumn{2}{|c|}{} & Count & $\%$ & Count & $\%$ \\
\hline Radiological grade & Grade 0 & 4 & $16.0 \%$ & 6 & $24.0 \%$ \\
\cline { 2 - 6 } & Grade 1 & 2 & $8.0 \%$ & 1 & $4.0 \%$ \\
\cline { 2 - 6 } & Grade 2 & 10 & $40.0 \%$ & 2 & $8.0 \%$ \\
\cline { 2 - 6 } & Grade 3 & 4 & $16.0 \%$ & 9 & $36.0 \%$ \\
\cline { 2 - 6 } & Grade 4 & 5 & $20.0 \%$ & 7 & $28.0 \%$ \\
\hline
\end{tabular}


Hanan M. H. Abuzeid, et al.,

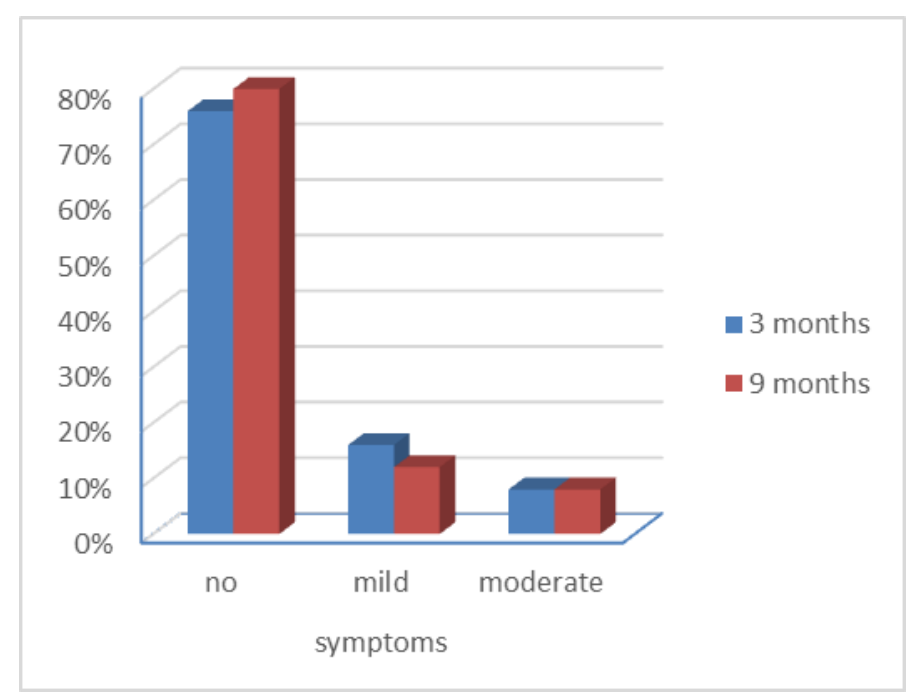

Diagram 2: Respiratory symptoms among patients.

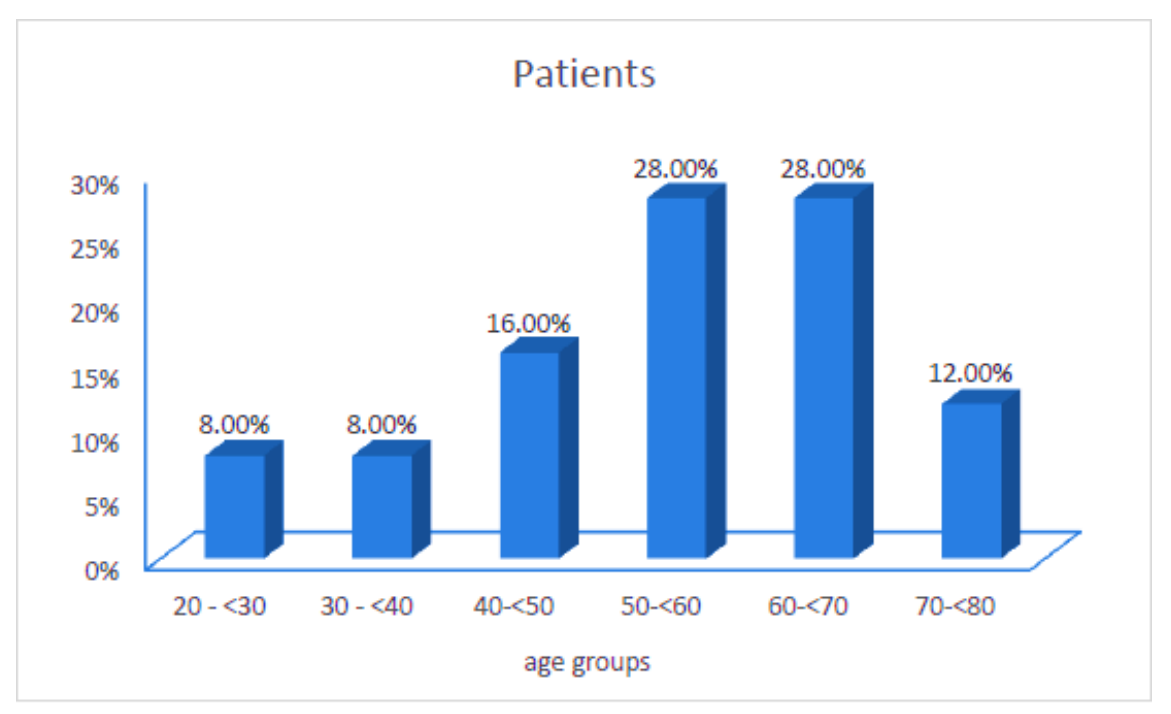

Diagram 3: Age distribution among patients.

Table 4: Correlation between grading scale and pre-existing chronic obstructive pulmonary disease (COPD).

\begin{tabular}{|c|c|c|c|c|c|c|}
\hline & \multicolumn{4}{|c|}{ COPD } & \multirow{3}{*}{$\mathrm{P}$ value } \\
\hline & & \multicolumn{2}{|l|}{$\mathrm{Y}$} & \multicolumn{2}{|l|}{$\mathrm{N}$} & \\
\hline & & Count & $\%$ & Count & $\%$ & \\
\hline \multirow[t]{5}{*}{ Radiological grade } & Grade 0 & 0 & $0.0 \%$ & 4 & $18.2 \%$ & \multirow[t]{5}{*}{0.018} \\
\hline & Grade 1 & 0 & $0.0 \%$ & 2 & $9.1 \%$ & \\
\hline & Grade 2 & 0 & $0.0 \%$ & 10 & $45.5 \%$ & \\
\hline & Grade 3 & 0 & $0.0 \%$ & 4 & $18.2 \%$ & \\
\hline & Grade 4 & 3 & $100.0 \%$ & 2 & $9.1 \%$ & \\
\hline
\end{tabular}


Table 5: Correlation between grading scale and radiation fields.

\begin{tabular}{|c|c|c|c|c|c|c|}
\hline & \multicolumn{4}{|c|}{ Radiation type } & \multirow[b]{2}{*}{$P$ value } \\
\hline & & \multicolumn{2}{|c|}{ Tangential beam } & \multicolumn{2}{|c|}{ Supraclavicular beam } & \\
\hline & & Count & $\%$ & Count & $\%$ & \\
\hline \multirow{5}{*}{$\begin{array}{l}\text { Radiological } \\
\text { grade }\end{array}$} & Grade 0 & 4 & $25.0 \%$ & 0 & $0.0 \%$ & \multirow[t]{5}{*}{0.021} \\
\hline & Grade 1 & 2 & $12.5 \%$ & 0 & $0.0 \%$ & \\
\hline & Grade 2 & 8 & $50.0 \%$ & 2 & $22.2 \%$ & \\
\hline & Grade 3 & 1 & $6.3 \%$ & 3 & $33.3 \%$ & \\
\hline & Grade 4 & 1 & $6.3 \%$ & 4 & $44.4 \%$ & \\
\hline
\end{tabular}

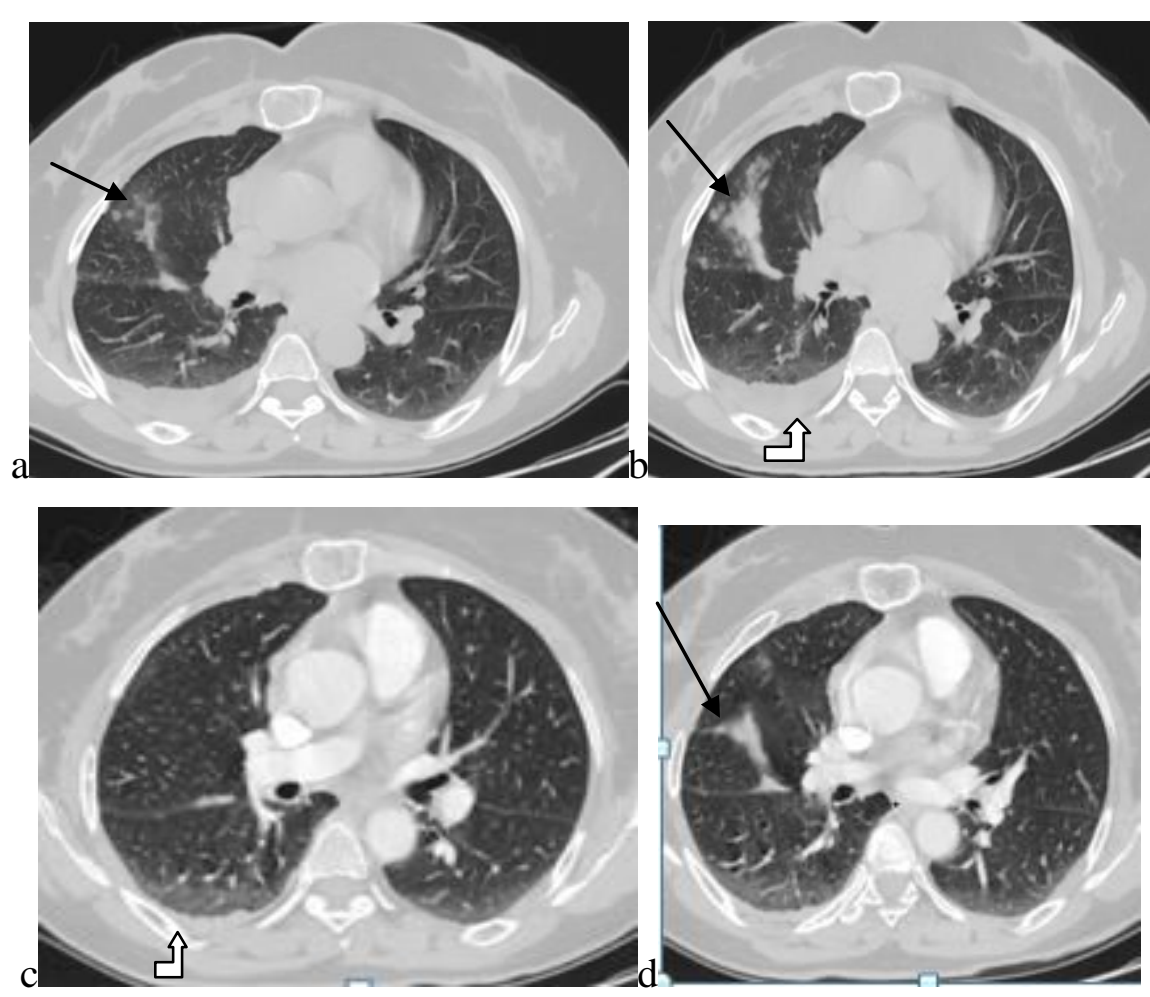

Figure 1: A 45 years old female patient with right breast cancer managed by breast conserving surgery followed by adjuvant chemotherapy and tangential field irradiation presented by mild cough on follow up 3 months $(a, b) C T$ chest showed ground glass attenuation, nodular and consolidative patch of the lateral segment of the middle lobe (black arrows) with mild right pleural effusion(white arrow)...(Grade 2). On follow up after 9 months (c, d) CT showed patch of consolidation with fibrosis of the middle lobe (black arrow) as well as minimal right pleural effusion (white arrow)...(Grade 3). 


\section{Hanan M. H. Abuzeid, et al.,}

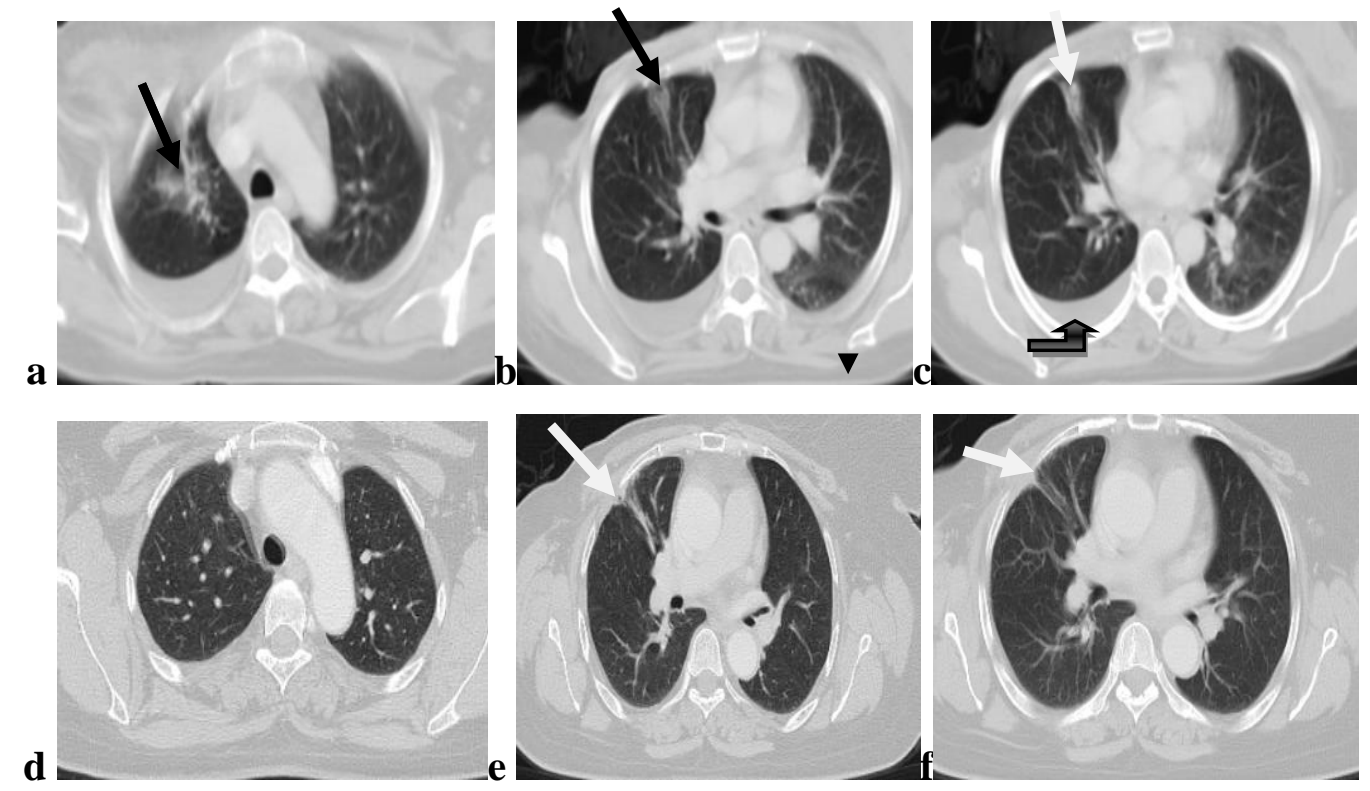

Figure 2: A 65 years old woman patient with carcinoma in right breast received supraclavicular beam irradiation on follow up after 3 months ( $a, b, c)$ axial CT was done showing ground glass attenuation, consolidation (black arrows) and fibrosis( white arrow) in right upper lung lobe...(Grade 3) as well as right pleural effusion ( curved arrow) on follow up after 9 months (d, e, f) axial CT showed sub pleural radiation fibrosis lung tissue adjacent to treated chest wall region( white arrows) helping to confirm that the cause is radiation induced lung changes ....(Grade3).

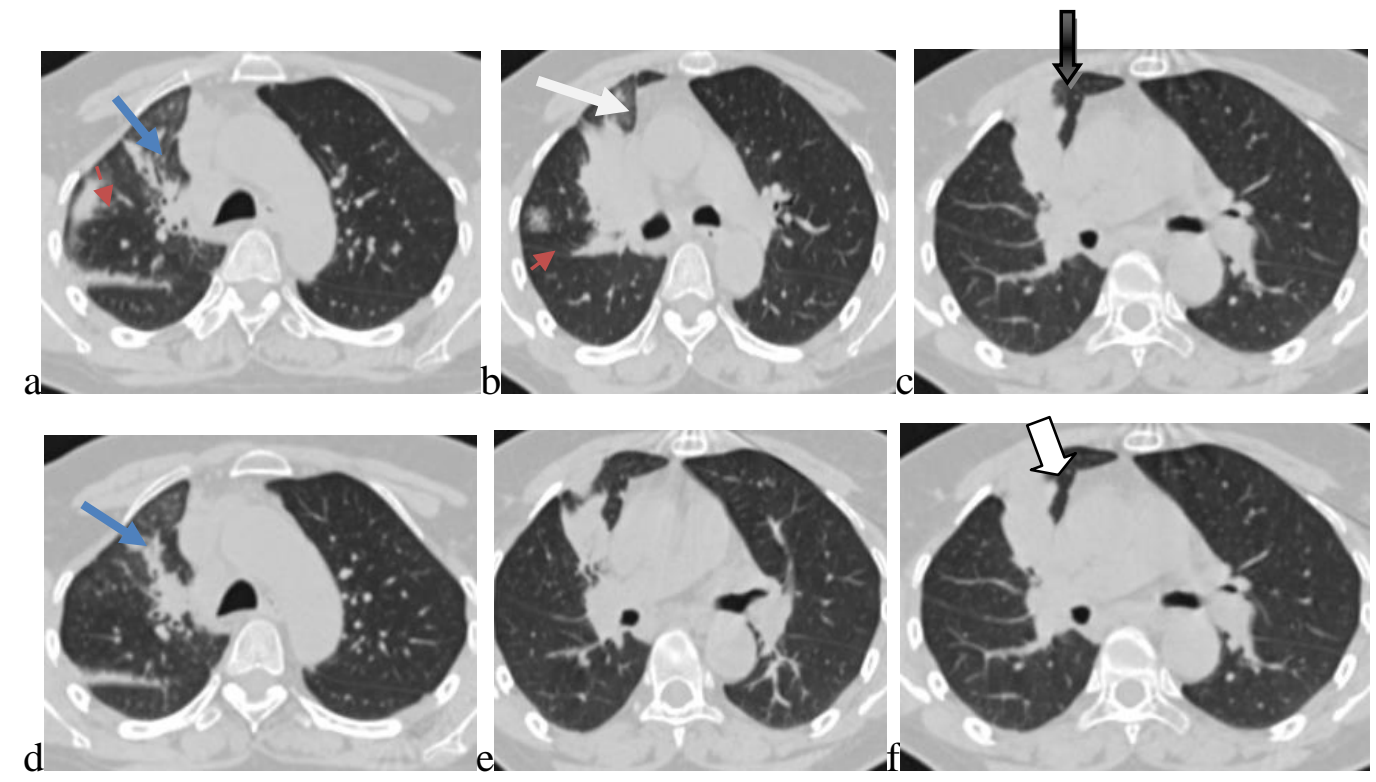

Figure 3: A 72 years old woman patient with right breast cancer managed by MRM, adjuvant chemotherapy and supraclavicular beam irradiation on follow up after 3 months (a, b, c)axial CT showed ground glass attenuation( white arrow ), consolidation(red arrows),fibrosis( black arrow) ,tractional bronchiectasis( blue arrow) in right upper lung lobe confined to the fissure...(Grade 4) on follow up after 9 months (d, e, f) axial CT showed consolidation and fibrosis(white arrow),tractional bronchiectasis(blue arrow) in right upper lung lobe, with related pleural thickening...(Grade 4). 

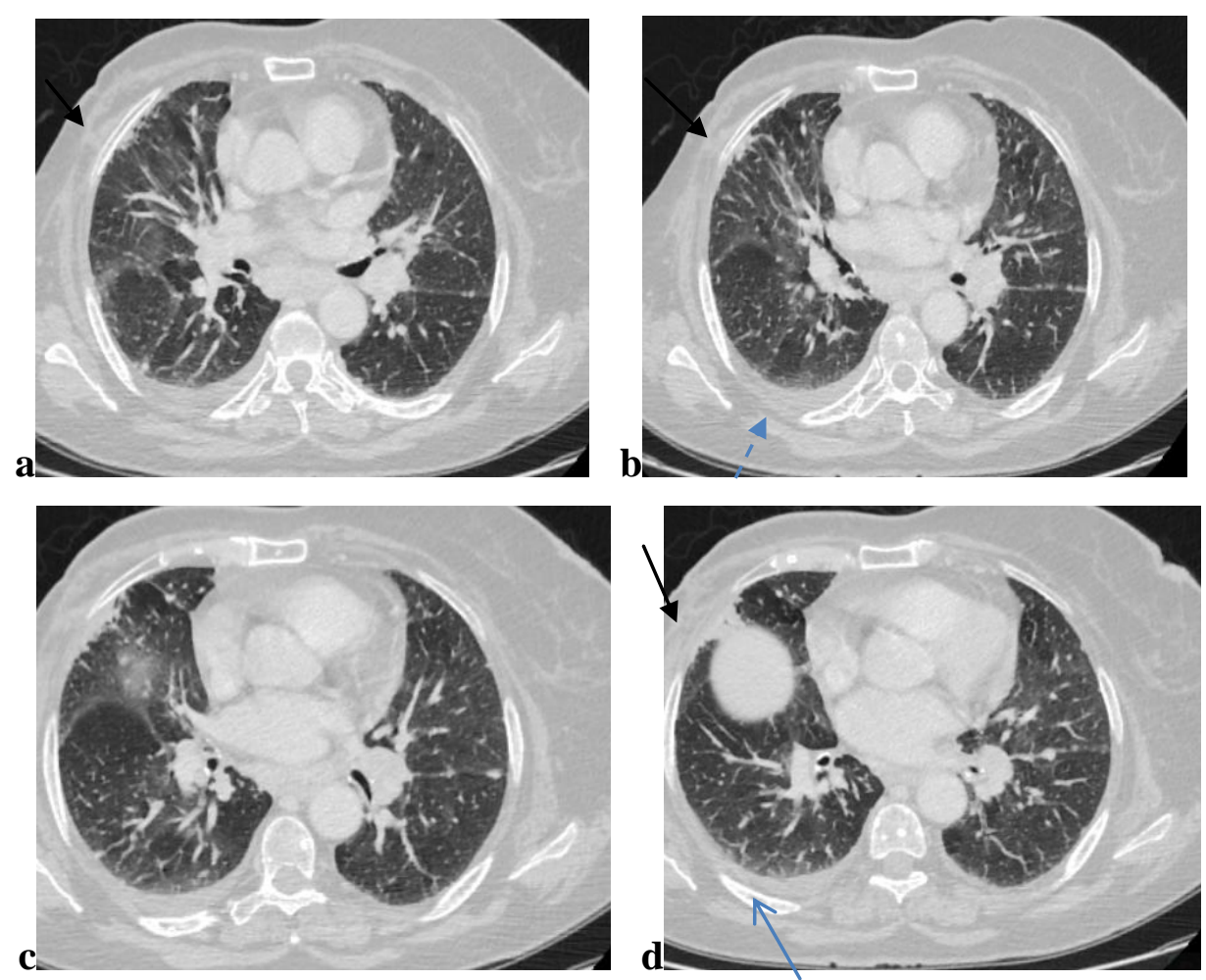

Figure 4: A 65 years old female patient presented with right breast cancer, with previous history of COPD managed with chemo-radiotherapy. Presented by moderate dyspnea and cough CT was done on 3 months and 9 months follow up. (a, b, c, d) axial CT showed diffuse mosaic attenuation with ground glass opacities, consolidation, fibrosis in the right upper lung lobe (black arrows) with related pleural thickening as well as right mild pleural effusion (blue arrow)...(Grade 4) with stationary course.

\section{DISCUSSION:}

In breast cancer, postoperative thoracic radiotherapy is widely used in order to reduce the risks of loco-regional recurrence and to improve overall survival. Lung is one of the relevant organs at risk in planning radiotherapy for breast cancer. Two major features are characteristics of RILD: first, lung injury is generally confined to the fields of radiation which are therefore important to know for correct interpretation; and second, it does not conform to anatomic boundaries (i.e. the fissures) which may be different from lung infiltration due to other diseases.

Different pattern of RILD occurred after three months of radiotherapy as follow; ground glass opacities in 15 cases, consolidation with air bronchogram in 13 cases, atelectactic bands in 9 cases, Fibrosis with traction bronchiectasis in 5 cases, pleural effusion 5 cases, pleural thickening in 3 cases (Tab 2). Ground glass opacities and areas of consolidation with air bronchogram were the most common finding associated with early RILD. After 9 months of radiotherapy different pattern of RILD as follow; ground glass opacities in 8 case, consolidation with air bronchogram in 9 cases, atelectactic bands in 16 cases, Fibrosis with traction bronchiectasis in 6 cases, pleural effusion in 3 case, pleural thickening in 5cases (Tab 2). So areas of atelectactic bands were the most common finding associated with delayed RILD.

According to Vassilios's scale grading of radiation induced lung disease as follow: At 3 months follow up by CT imaging. The imaging findings are grade 0 ( 4 cases 16 $\%$ ), grade 1 ( 2 cases $8 \%$ ), grade 2 ( 10 cases $40 \%$ ), grade 3 ( 4 cases $16 \%$ ), grade 
4 (5 cases 20\%). At 9 months follow up by $\mathrm{CT}$ imaging. The imaging findings are grade 0 (6 cases $24 \%$ ), grade 1 ( 1 cases $4 \%$ ), grade 2 ( 2 cases $8 \%$ ), grade 3 ( 9 cases 36 $\%)$, grade 4 (7 cases $28 \%$ ) (Tab 3 ).

In the current study after the completion of radiotherapy involving the lung, radiographic pulmonary changes on computed tomography (CT) are reported in $84 \%$ of cases at three months and $76 \%$ of cases at nine months after radiotherapy and are thus common. The incidence of radiation fibrosis was observed: $56 \%$ of patients were presented with radiation fibrosis at early phases however radiation fibrosis was noted at $88 \%$ of patients after 9 months follow up. This could be explained by what has been reported by Chisam \& Douglas $^{(8)}$,they reported that fibrosis can occur without previous pneumonitis, but once pneumonitis occurs, fibrosis is almost certain to take place. Otani et al., ${ }^{(9)}$ reported that after the completion of radiotherapy involving the lung, radiographic pulmonary changes on computed tomography (CT) are reported in $78 \%$ of cases at 3-9 months after radiotherapy and are thus common. Valli et al., (4) also reported that radiation induced lung injury occurs in almost 10-15\% of patients treated with adjuvant radiotherapy for breast cancer. However, this may be due to the more advanced technique of computerized radiotherapy planning in western countries.

Regarding the respiratory symptoms of the patients at 3 months, 6 cases (24\%) symptomatic, however 19 cases $(76 \%)$ were asymptomatic. At 9 months follow up 5 case cases $(20 \%)$ symptomatic ranging from mild to moderate symptoms, however 20 cases $(80 \%)$ were asymptomatic (Diag 2). RILD is not correlated with the presence of chest related symptoms. This results were coincided with Benveniste et al., (10) , Hanania et al., (7) that the symptoms of radiation pneumonitis (RP) varies from asymptomatic in most of the patients to mild and moderate symptoms in few cases.

The degree of the lung injury after irradiation includes dosimetric and non dosimetric parameters:

Regarding to the dosimetric factors Radiation induced damage to normal lung parenchyma remains a dose limiting factor in chest radiotherapy, and can involve other structures within the thorax in addition to the lungs ${ }^{(11)}$. It is important to clear out that the total dose received in all our patients was higher than the threshold value reported for the development of radiation pneumonitis as it was always $\geq 50$ Gray and the incidence of radiation induced lung damage in the current study was which is coincided with Hanania et al., ${ }^{(7)} \&$ Valli et al., ${ }^{(4)}$ reported also that radiation oncologists attempt to limit RILI by minimizing the volume of lung receiving V 20 Gray or 30 Gray (V20 and V30, respectively), as a higher V20 in particular has been shown to be predictive of RP. Higher mean lung doses and irradiation of the lower lung fields also correlate with increased incidence of pneumonitis.

Regarding to history of smoking, COPD, and interstitial lung disease all are associated with increased risk, 3 patients were suffering from. Following the statistical process of the results, a high correlation of COPD was found $(\mathrm{P}=0.018)$ (Tab 4).this result is coincided Kouloulias et al., ${ }^{(12)}$, Jeba et al., ${ }^{(13)}$ \& Hanania et al., ${ }^{(7)}$ reported that all patients with history of smoking, COPD, and interstitial lung disease are all associated with increased risk of radiation pneumonitis.

Regarding the patient age as a risk factor for development of RILD, in the current study found that older patients are believed to have poorer tolerance to radiation therapy with higher incidence was observed in patients with age $\geq 50$ years (Diag 3). 
Kong and Wang ${ }^{(14)}$ reported that older patients are believed to have poorer tolerance to radiation therapy and are often given less aggressive treatment. Indeed, some studies and a pooled analysis of 13 studies before 2012 showed older age significantly increased the risk of RILD, but others did not find an association between age and the risk of RILD and Hanania et al., ${ }^{(7)} \&$ Valli et al., ${ }^{(4)}$, reported that patients Age > 50 years old more liable for RILI.

Regarding the patient gender as a risk factor for development of radiation pneumonitis, in the current study radiation pneumonitis occurred in females more than in males. However, this could be due to all patients are female in our study, as most of our patients were presented with breast cancer which is more common in females, Kong and Wang ${ }^{(14)}$, reported that the effect of gender on RILT is not clear. Women often have smaller lung volumes than men and they are prone to have autoimmune diseases that may predispose to a greater risk of lung injury however Vogelius and Bentzen ${ }^{(15)}$,reported that no association of gender with RP risk was seen. Therefore, gender should not be given too much consideration when prescribing RT.

Regarding radiation regimens the current study showed (16 cases 64\%) 4 cases managed with chest wall and (9 cases $36 \%$ ) with supraclavicular field treatment (Tab 5 $\&$ Fig 2). Following the statistical process of the results, a high correlation of supraclavicular field was found $(\mathrm{P}=$ 0.021)Which is coincided with Hanania et al., ${ }^{(7)}$ that in patients with breast cancer, chest wall irradiation with electrons and supraclavicular field treatment are correlated with increased risk.

Radiation induced organizing pneumonia rarely to occur the incidence was $4 \%$ at 3 months follow up with complete resolution at 9 months follow up (Diag 1), unlike the typical radiation induced pneumonitis pattern seen in the radiation field, this organizing pneumonia pattern appears as migratory opacities outside of the radiation field 2-9 months after the completion of radiation therapy and is believed to be immunologically mediate ${ }^{(10)}$. This low incidence is consistent with Otani et al., ${ }^{(9)} \&$ Sato et al., ${ }^{(16)}$ who described organizing pneumonia (OP) is a well known adverse effect that is rare but significant. Radiation induced OP is reported to occur in $\sim 1-3 \%$ of breast cancer patients who receive postoperative RT.

Pleural changes following radiotherapy:

In the current study at 3 months follow up pleural effusion seen in 5 cases $20 \mathrm{~S} \%$, pleural thickening seen in 3 cases $12 \%$. After 9 months of radiotherapy pleural effusion seen in 3 cases $12 \%$ two of them seen with lung metastasis, pleural thickening seen in 5 cases $20 \%$ (Tab 2). Benveniste et al., ${ }^{(10)}$ at imaging radiation induced inflammatory changes in the pleura manifest as pleural effusions. They are readily detected at CT and seen in 6\%-23\% of patients during radiation therapy delivery and in most patients after thoracic irradiation. Pleural effusions are characteristically seen within 6 months after the completion of radiation therapy. They are usually small, persist for months, disappear spontaneously and do not increase spontaneously after a period of stability.

\section{Conclusion:}

To correctly interpret chest imaging findings after thoracic irradiation, the radiologist must be familiar the date of the last radiation therapy delivery, the treatment dose, and the treatment field. It is necessary to know and to understand the expected complications for the interpretation of follow-up images in patients after radiation therapy for breast cancer. This information helps in distinguishing radiation induced changes from infection or malignancy progression. 


\section{REFERENCES:}

1. DeSantis C, Ma J, Bryan L, and Jemal A, (2014). Breast cancer statistics.CA Cancer J Clin; 64:52-62.

2. Oie Y, Saito Y, Kato M, et al,(2013). Relationship between radiation pneumonitis and organizing pneumonia after radiotherapy for breast cancer . Radiation Oncology 8:56.

3. Khashper A, Gruber J M, Fraser R S, et al,(2015). Review of Thoracic Imaging Findings Unique to Women . Canadian Association of Radiologists Journal 66223 -230 .

4. Valli M, Cekani E, Cima S,Richetti A,(2017).Special Issue on Radiation Therapy for Breast Cancer - Radiation Side Effects. Sci J Nucl Med Radiat Ther.;1(1): 016-031.

5. Giridhar P, Mallick S, Rath G K, et al, (2015). Radiation Induced Lung Injury: Prediction, Assessment and Management. Asian Pac J Cancer Prev,; 16: 2613-2617.

6. Giménez A, Franquet T, Hidalgo A, (2011). Intrathoracic manifestations of breast cancer. Radiology. 53(1):7-17.

7. Hanania A N, Mainwaring W, Ghebre Y T, et al,(2019).Radiation-Induced Lung Injury Assessment and Management: CHEST; 156(1):150-162.

8. Chisam M, Douglas R. (2016) Radiation pneumonitis. Medscape-Drugs \& Diseases 2002. Available from: www.eMedicine.com.

9. Otani K, Seo Y, Ogawa K, (2017). Radiation-Induced Organizing Pneumonia: A Characteristic Disease that Requires Symptom-Oriented Management: Int. J. Mol. Sci., 18, 281.
10. Benveniste M F, Gomez D, Carter B W, et al,(2019).Recognizing Radiation Therapy related Complications in the Chest. Radiographic; 39:344-366.

11. Olivier $\mathrm{K} R$, Peikert $\mathrm{T}$, Jett $\mathrm{J} R$, et al,(2003).Spiral CT, Multislice CT. Principles of CT. In: Prokop M, Galanski M (eds). Spiral and Multislice computed tomography of the body. Stuttgart, Germany: Georg Thieme Verlag; 1-42.

12. Kouloulias V, Zygogianni A, Efstathopoulos E, et al, (2013).Suggestion for a new grading scale for radiation induced pneumonitis based on radiological findings of computerized tomography: correlation with clinical and radiotherapeutic parameters in lung cancer patients. Asian Pac J Cancer Prev 14(5): 2717-22.

13. Jeba J, Isiah R, Subhashini J, et al, (2015). Radiation Pneumonitis After Conventional Radiotherapy For Breast Cancer: Journal of Clinical and Diagnostic Research. Jul, Vol9(7): XC01-XC05.

14. Kong F M, Wang Sh,(2015). Nondosimetric risk factors for radiation-induced lung toxicity. Semin Radiat Oncol. April; 25(2): 100-109.

15. Vogelius IR, Bentzen SM, (2012). A literature-based meta-analysis of clinical risk factors for development of radiation induced pneumonitis. Acta Oncol; 51(8):975-983. (PubMed: 22950387).

16. Sato H, Ebi J, Tamaki T, et al, (2018). Incidence of organizing pneumonia after whole-breast radiotherapy for breast cancer and risk factor analysis: Journal of Radiation Research, Vol. 59, No. 3, pp. 298-302. 
دور الأشعة المقطعية متعددة المقاطع في تقييم التغيرات بالرئهة والغشاء البلوري بعد العلاج الإشعاعي لسرطان الثدي

حنان حمحل حنفي أبوزيد ؛ ايمان أحمد شوقي جنيدي؛ هيثم كحم ناصر؛ نشوي جاد بسيوني جاد

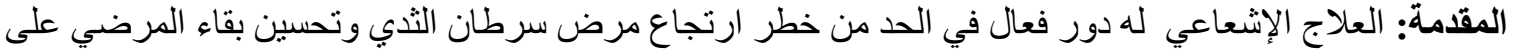

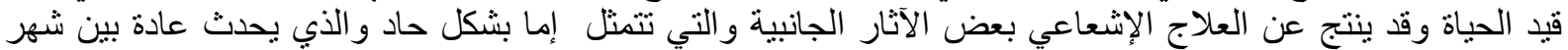

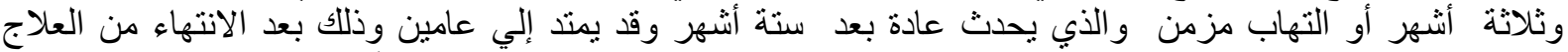

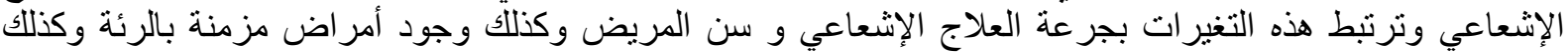

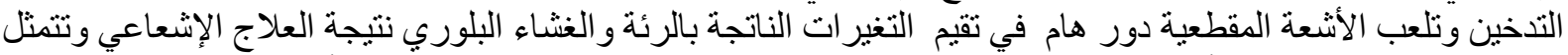

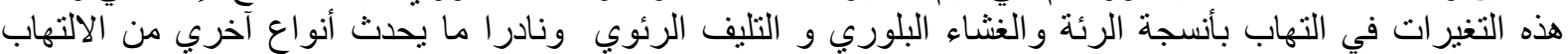
بالرئة.

الهـف من البحث: ايضاح دور الاشعة المقطعية متعددة المر احل لتقييم التغيرات الناتجة بالرئة والغثاء البلوري بعد العلاج الاشعاعي لمرضي سرطان الثني.

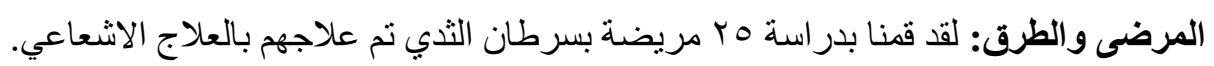

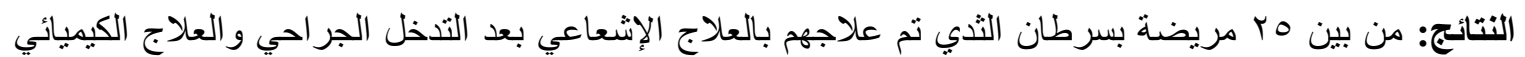

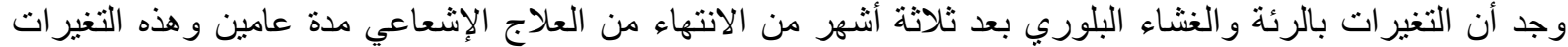

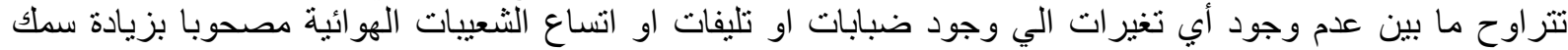
الغثاء البلوري والارتشاح البلوري.

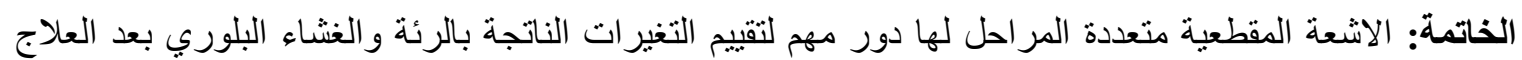
الاشعاعي لمرضي سرطان الثندي. 